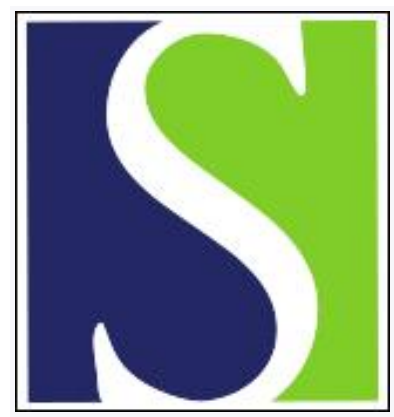

Scand J Work Environ Health 2016;42(6):510-519

https://doi.org/10.5271/sjweh.3597

Published online: 03 Oct 2016, Issue date: 01 Jun 2016

Long-term effectiveness of an educational and physical intervention for preventing low-back pain recurrence: a randomized controlled trial

by Chaléat-Valayer E, Denis A, Abelin-Genevois K, Zelmar A, Siani-Trebern F, Touzet S, Bergeret A, Colin C, Fassier J-B

This paper notes that a careful case definition of workers with previous history of low-back pain (LBP) is needed to better characterize sub-groups based on their recurrences profile. Workers with highly recurrent LBP may require a stepped secondary prevention in order to prevent recurrences and sick leave. The value of a workplace component reducing physical and psychosocial risks in secondary prevention of LBP must be explored.

Affiliation: Univ Lyon, Univ Lyon 1, IFSTTAR, Hospices Civils de Lyon, UMRESTTE, UMR_T9405, Domaine Rockefeller, 69373 Lyon Cedex 08, France. jean-baptiste.fassier@univ-lyon1.fr

Refers to the following texts of the Journal: 2014;40(1):74-81 2015;41(2):153-163

Key terms: back pain; educational intervention; intervention; low-back pain; occupational health; occupational health; pain; pain recurrence; physical exercise; physical intervention; randomized controlled trial; RCT; secondary prevention; sick leave; workplace

This article in PubMed: www.ncbi.nlm.nih.gov/pubmed/27779639 


\title{
Long-term effectiveness of an educational and physical intervention for preventing low-back pain recurrence: a randomized controlled trial
}

\author{
by Emmanuelle Chaléat-Valayer, MD, ${ }^{1}$ Angélique Denis, MSc, ${ }^{2}$ Kariman Abelin-Genevois, MD, PhD, ${ }^{1}$ \\ Amélie Zelmar, MPH, ${ }^{2}$ Fabienne Siani-Trebern, $P T,{ }^{3}$ Sandrine Touzet, MD, PhD, ${ }^{2}$ Alain Bergeret, MD, \\ $P h D,{ }^{4}$ Cyrille Colin MD, PhD, ${ }^{2}$ Jean-Baptiste Fassier, MD, PhD ${ }^{4}$
}

\begin{abstract}
Chaléat-Valayer E, Denis A, Abelin-Genevois K, Zelmar A, Siani-Trebern F, Touzet S, Colin C, Fassier J-B. Long-term effectiveness of an educational and physical intervention for preventing low-back pain recurrence: a randomized controlled trial. Scand J Work Environ Health. 2016;42(6):510-519. doi:10.5271/sjweh.3597
\end{abstract}

\begin{abstract}
Objective Low-back pain (LBP) is a common and recurrent condition, but the evidence is scarce about effective strategies to prevent recurrence and disability in the longer term. This study investigated the effect of a light exercise program, initiated in the workplace and continued at home, in reducing recurrence of LBP episodes among healthcare workers.
\end{abstract}

Methods A total of 353 healthcare workers from ten hospitals were enrolled in a randomized controlled trial (RCT) and were randomized to the intervention or control groups, the latter of which received usual care. The intervention comprised three steps: (i) a 2-hour education session, (ii) five weekly 90 -minutes exercise training sessions in the workplace, and (iii) a home-based self-managed exercise program. The main outcome was recurrence of LBP with sick-leave at 24-months follow-up.

Results At two-year follow-up, 35 workers (24\%) in the intervention group and 31 workers (21\%) in the contro group had at least one LBP recurrence with sick leave. No effect was observed between groups [odds ratio (OR) $1.22,95 \%$ confidence interval $(95 \% \mathrm{CI}) 0.67-2.23, \mathrm{P}=0.516]$. The intervention was effective in reducing fear avoidance with a mean reduction of $-3.6(95 \% \mathrm{CI}-4.8-2.4)$ points on the fear-avoidance beliefs questionnaire score for physical activity (FABQ-P) in the intervention group compared with -1.3 (95\% CI -2.2- - 0.3$)$ points in the control group $(\mathrm{P}<0.05)$. It was also effective in improving muscle endurance with a mean increase of 13.9 (95\% CI 3.3-24.5) minutes on the Sorensen test in the intervention group compared with -8.3 (95\% CI-17.5-0.9) minutes in the control group $(\mathrm{P}<0.05)$. Healthcare utilization was reduced in the intervention group for painkillers, medical visits, imaging and outpatient physiotherapy.

Conclusion It was not possible to conclude about the effectiveness of a light exercise program to reduce LBP recurrence episodes in the long-term in healthcare workers. However, it was effective to improve muscle endurance, and to reduce fear-avoidance beliefs and healthcare utilization. Further studies are necessary in order to identify effective interventions to reduce LBP recurrence and related sick-leaves.

Key terms occupational health; physical exercise; RCT; secondary prevention; sick leave; workplace.

Low-back pain (LBP) is both a common and recurrent condition, for which estimates of recurrence at one year range from $24-80 \%$ (1). In France, over a one year period more than half the population reported LBP (2), and it is the first condition that contributes to disability (3). Preventing work disability due to LBP has been acknowledged as a public and occupational health prior- ity in many countries. Given the prevalence of LBP, it has been argued that a focus on secondary prevention might be worthwhile, aiming at reducing recurrence of LBP episodes and/or at reducing chronic pain and work disability due to $\operatorname{LBP}(4,5)$.

In contrast to the available evidence about LBP prognosis (6), screening instruments $(7,8)$, interventions

1 Service de Médecine physique et réadaptation, Centre médico-chirurgical de réadaptation des Massues Croix Rouge Française, Lyon, France.

2 Pôle Information Médicale Evaluation Recherche clinique, Hospices Civils de Lyon; University of Lyon, Health Services and Performance Research (HESPER, EA 7425), Lyon, France.

3 Service de Médecine Physique Réadaptation, Centre Hospitalier Ardèche Méridionale, Vals les bains, France.

4 Univ Lyon, Univ Lyon 1, IFSTTAR, Hospices Civils de Lyon, UMRESTTE, UMR_T9405, Lyon, France.

Correspondence to: Dr Jean-Baptiste Fassier, UMRESTTE, Domaine Rockefeller, 69373 Lyon Cedex 08, France. [E-mail: jean-baptiste. fassier@univ-lyon1.fr] 
at the chronic phase (9), work-directed (10) and workplace-based interventions (11) for disabled workers, evidence is remarkably scarce about effective strategies to prevent LBP recurrence. A review of exercises for the prevention of LBP recurrence (12) identified only four studies evaluating so-called post-treatment interventions, delivered after the resolution of an LBP episode in order to prevent new episodes. Based on two studies, there was very low quality evidence that post-treatment exercises could reduce the number of days on sick leave at mid-term follow-up $(13,14)$. This positive effect was lacking at long-term follow-up (13), and new trials were deemed necessary to figure out which strategies could prevent LBP recurrence and related work disability in the long term (12).

Healthcare workers are particularly exposed to LBP biomechanical risk factors such as bending and manual handling of loads and patients $(15,16)$. In France, nurse auxiliaries are the first occupational category exposed to manual handling, with an estimate of 169000 workers exposed (17). As a consequence, the healthcare sector is one of the most badly affected by LBP. The main goal of the PRESLO study (French acronym for "secondary prevention of LBP") was to evaluate the longterm effectiveness of a secondary prevention program based on education and exercise therapy to prevent LBP recurrence and related work disability among hospital workers. We wanted to test the hypothesis that a light exercise program, initiated in the workplace and continued at home, is effective in the long-term to reduce LBP recurrence episodes (and thus sick leaves related to LBP) among workers with a previous history of LBP compared to a control group with usual care.

\section{Methods}

\section{Study design}

A 2-arm single blinded randomized controlled study was conducted among healthcare workers recruited from ten hospitals of a large public consortium employing 16000 workers (Hospices Civils de Lyon) in Lyon, France, from October 2008 to July 2011. The participants were randomly allocated to the intervention or control groups. The relevant authorities (Ethics Committee, DirectorateGeneral for Health and Consumers, National Commission for Data Protection and Liberties - CNIL France) approved the study, which was authorized by the direction of the Hospices Civils de Lyon, and the Committees for Health, Safety and Working Conditions (CHSCT) of each participating hospital. The study was registered in ClinicalTrials.gov (NCT00782925) and its protocol has been published elsewhere (18).

\section{Recruitment and flow of participants}

Participants were recruited by their occupational physician (OP), either during their annual follow-up visit or on their own request following communication campaigns that were regularly carried out in the Hospices Civils de Lyon (electronic newsletters and other hospital newspapers).

The inclusion criteria were presenting, over the previous three years, $\geq 1$ episode(s) of LBP of $<3$ months' duration, with or without sick leave (LBP, lumbosciatica or acute or sub-acute cruralgia were considered). The exclusion criteria were previous history of back surgery (for spine fractures, discal hernia in two or more locations, lumbar or lumbosacral arthrodesis in three or more locations), radiculalgia with sequelary motor deficiencies or pure radiculalgia, chronic LBP for $>3$ months, current episode of LBP, psychiatric and/or behavioral disorders, unstable cardiac pathology, insufficient mastery of the French language, and pregnancy.

\section{Randomization and blinding}

Following the inclusion visit, participants were randomly assigned in permuted blocks of four, stratified by participating hospitals. The randomization lists were computed by an independent service operating outside the workplace using $\mathrm{SAS}{ }^{\circledR}$ statistical analysis software (version 9.1, SAS Institute Inc, Cary, NC, USA). Each participant was informed by mail of his assignment and, where appropriate, the timetable for the program sessions was included. Participants were carefully instructed to conceal their allocation from the OP who performed their 1- and 2 -year follow-up evaluation. The OP had no contact with the physiotherapists who carried out the intervention and thus remained blinded to the allocation of the participants during the intervention and at 1- and 2-year follow-up visits. For obvious reasons, the participants and the program providers (physiotherapists) could not be blinded. Participants were informed prior to the study that people allocated to the control group would receive the program after the trial if it was proven effective.

\section{Intervention}

The exercise therapy program comprised three steps (18). First, a 2-hour education session was delivered to the participants about LBP, pain pathways, fear-avoidance beliefs and coping. Key messages focused on pain management, staying active and adaptive coping during LBP episodes. Second, coaching 8-10 participants, one physiotherapist delivered five weekly 90 -minute training sessions. The sessions were based in the workplace, and considered as working time. Each exercise session was composed of a 15-minute warm-up with rhythmic exer- 
cises, followed by 60 minutes of stretching and mobilizing the spine (including relaxation of the lumbar spine and stretching of the hamstrings, gluteals, quadriceps, psoas and adductors, as well as pelvic tilt awareness exercises) and finally, 15 minutes involving respiratory and postural work. The last step of the program was home-based with a booklet for self-managed home exercising and the French version of the Back Book (19). The participants were instructed to perform the exercises at home daily for approximately ten minutes. Control group members did not benefit from specific treatment of LBP aside from their usual care.

\section{Outcomes}

$\angle B P$ recurrence. The OP measured LBP recurrence outcomes among participants at two years follow-up after the completion of the training sessions, with an intermediate data collection point at one year. The primary outcome was the percentage of participants with $\geq 1$ recurrence of LBP with sick leave. Other outcomes were the average time to recurrence of LBP, the percentage of participants with sick leave related to chronic LBP (pain for $>3$ months), the participant's compliance with the program, and their satisfaction. All other outcomes were measured by physiotherapists at 18 -month followup after completion of the training sessions.

Psychological outcomes. Pain was assessed using the Saint-Antoine pain questionnaire (QDSA) (20) and visual analog scale (VAS). Anxiety and depression were measured with the hospital anxiety and depression (HAD) questionnaire (21). Coping strategies and fearavoidance were measured with the French versions of the coping strategy questionnaire (CSQ) (22) and fear avoidance beliefs questionnaire (FABQ) (23). Health related quality of life was evaluated with the 12 -item short form (SF-12) questionnaire (24).

Functional and physical outcomes. Functional disability was assessed by the French version of the Quebec back pain disability scale (QBPDS) (25). Lumbar flexibility was tested using the Schöber Mac Rae test. Pelvic flexibility was tested by the finger-to-ground distance. Muscle endurance was tested by the Shirado test (abdominal wall) and Sorensen test (lumbar extensors).

Healthcare utilization. We assessed for painkillers, visits to the general practitioner and/or specialists, imaging and outpatient physiotherapy.

Process evaluation. Attendance of the training sessions and observance of the home-based exercises at 6,12 and 24 months were measured. The participant's appreciation of the program was explored by a satisfaction ques- tionnaire and by means of semi-structured interviews conducted one year after the completion of the training sessions with 21 participants identified by purposive sampling to represent a variety of jobs and hospitals. The interview guide was drawn to explore the workers' representations of LBP and their initial expectations about and personal experience with the program. All interviews were transcribed to perform a qualitative thematic content analysis with Atlas.ti software, the results of which results have been published elsewhere (26).

\section{Statistical analysis}

Assuming a recurrence rate of LBP episodes of $45 \%$ after two years of follow-up, a population of 310 healthcare workers in each group was required to detect a $25 \%$ reduction in the risk of LBP recurrence with sick leave between the intervention and control groups with a power of $80 \%$ and alpha risk of $5 \%$. With an estimation of $5 \%$ dropouts, 325 healthcare workers per group were needed.

Baseline characteristics of healthcare workers were compared between the study groups with the twosample t-tests or Wilcoxon's test, where appropriate, for quantitative data and the Pearson $\mathrm{Chi}^{2}$ test or Fisher's exact for categorical data. The intervention effect on outcomes (LBP recurrence with and without sick leave or number of LBP recurrences over the 2-year followup) was assessed using logistic model or Poisson model adjusted for baseline characteristics (age, LBP history 3 years prior to inclusion, FABQ-W). A Wald statistic was used to test the significance of each coefficient in the model. The intervention effect was given as adjusted odds ratio $\left(\mathrm{OR}_{\mathrm{adj}}\right)$ or relative risk (RR) with its $95 \%$ confidence interval $(95 \% \mathrm{CI})$. The time to first recurrence of LBP episode was compared between the study groups with Kaplan and Meier plot. The duration of sick leaves caused by LBP at 2-year follow-up was compared between the study groups with the Wilcoxon test. Additionally, a sensitivity analysis was performed for the main outcome by excluding workers with $\geq 2$ previous sick leaves for LBP over the three years prior to inclusion.

Changes in physical and psychosocial outcomes were analyzed according to the difference-in-difference (DID) approach (27) by testing for the effects of group (intervention versus control), time (baseline versus 18 month) and interaction between group and time. We used the interaction between group and time and its $95 \% \mathrm{CI}$ to estimate the mean of improvement in the intervention group compared with the control group. DID estimate captures the program effect in the intervention group, controlling for the effects of change over time in physical and psychosocial outcomes owing to factors other than the intervention itself. Compliance with the pro- 
gram and home-based exercises was compared between surveys at 6 and 24 months using the Wilcoxon signed rank test. Analyses were carried out in accordance with the principle of intention-to-treat. A per-protocol analysis was also performed, excluding all health workers who had failed to complete the intervention $(<5$ sessions). Statistical analyses were performed using SAS ${ }^{\circledR}$ 9.3 (SAS Institute Inc, Cary, NC, USA). $\mathrm{P}<0.05$ was considered to be statistically significant.

\section{Results}

\section{Study population}

A total of 353 healthcare workers were enrolled between October 2008 and July 2011. Figure 1 presents the patient flow over the course of the study. After exclusion of 11 subjects, 342 participants were randomized to either the control or intervention group. Table 1 shows

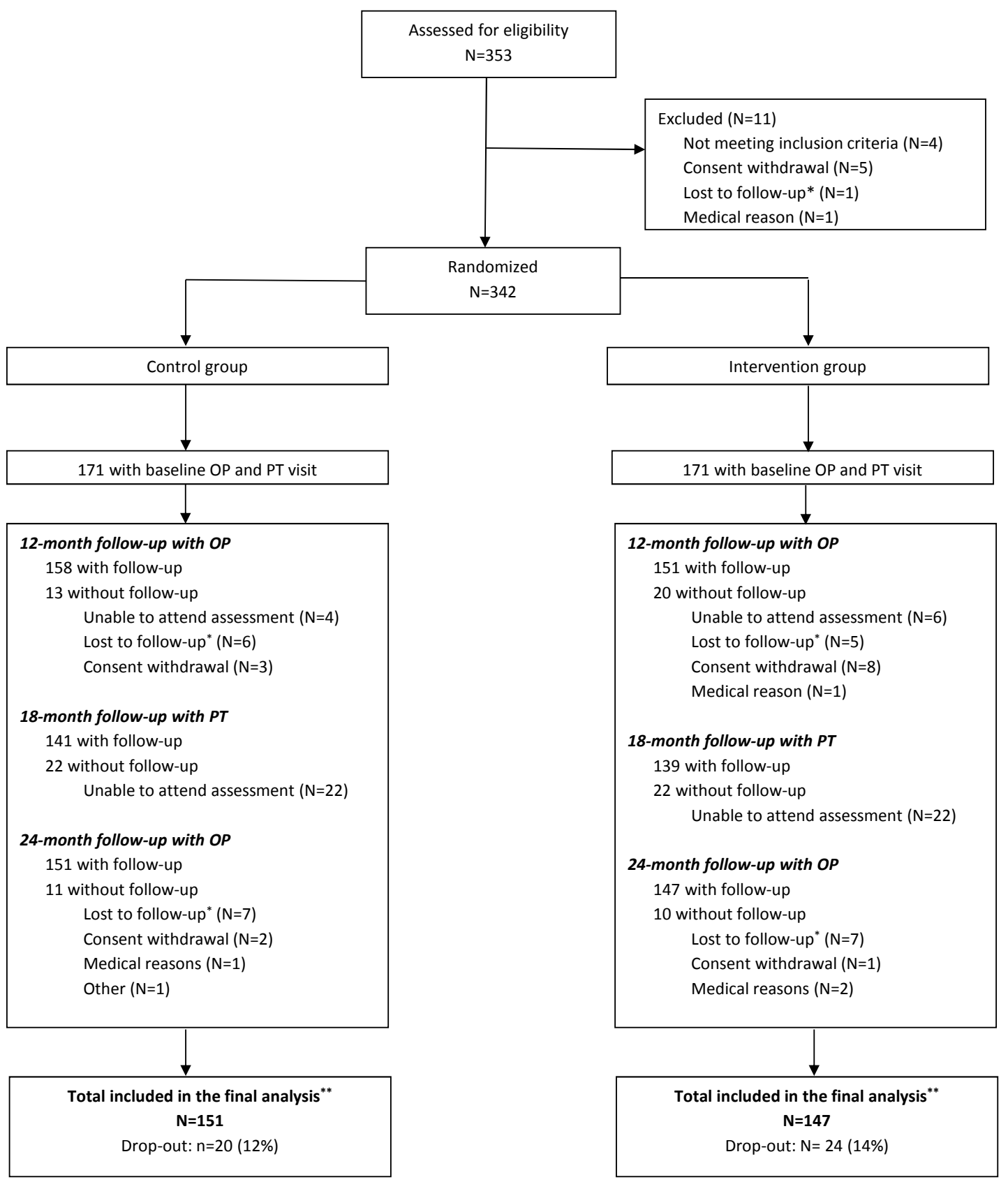

Figure 1. Participant recruitment flowchart. *Lost to follow-up: retirement, job transfer, laid-off, no news; ${ }^{* *}$ Number of patients with data for the primary outcome ( $\geq 1$ recurrence of low-back pain with sick leave over the 2-year period). [OP=occupational physician; $P T=$ physiotherapist] 
Table 1. Baseline characteristics of participants. [SD=standard deviation; Min-Max=minimum-maximum; VAS=visual analog scale; $\mathrm{GP}=$ general practitioner.]

\begin{tabular}{|c|c|c|c|c|c|c|c|c|c|c|c|c|}
\hline \multirow{2}{*}{$\begin{array}{l}\text { Low-back pain (LBP) history } \\
3 \text { years prior to inclusion }\end{array}$} & \multicolumn{6}{|c|}{ Intervention group $(\mathrm{N}=171)$} & \multicolumn{6}{|c|}{ Control group(N=171) } \\
\hline & Mean & SD & $\mathrm{N}$ & $\%$ & Median & Min-Max & Mean & SD & $\mathrm{N}$ & $\%$ & Median & Min-Max \\
\hline Length of history of back pain (year) & 12.8 & 9.5 & & & & & 14.5 & 10.8 & & & & \\
\hline \multicolumn{13}{|l|}{ Sick leaves due to LBP episodes } \\
\hline 0 & & & 82 & 48 & & & & & 96 & 56 & & \\
\hline 1 & & & 48 & 28 & & & & & 42 & 24 & & \\
\hline $2-4$ & & & 37 & 22 & & & & & 30 & 18 & & \\
\hline$\geq 5$ & & & 3 & 2 & & & & & 3 & 2 & & \\
\hline Duration of sick leave (days) & 15.0 & 34.5 & & & & & 16.0 & 33.2 & & & & \\
\hline Painful days per month & 6.2 & 5.1 & & & & & 6.5 & 5.6 & & & & \\
\hline VAS lumbar pain & & & & & 40 & $3-90$ & & & & & 35 & $0-100$ \\
\hline VAS radicular pain & & & & & 40 & $0-90$ & & & & & 40 & $4-80$ \\
\hline Medication use a & & & 165 & 97 & & & & & 166 & 97 & & \\
\hline GP or specialist visits & & & 157 & 92 & & & & & 164 & 96 & & \\
\hline Alternative treatments ${ }^{\mathrm{b}}$ & & & 151 & 88 & & & & & 147 & 86 & & \\
\hline Spine surgery & & & 5 & 3 & & & & & 5 & 3 & & \\
\hline Spondylolisthesis or scoliosis & & & 66 & 39 & & & & & 75 & 44 & & \\
\hline Load- or patient-handling training course & & & 74 & 43 & & & & & 72 & 42 & & \\
\hline \multicolumn{13}{|l|}{ Healthcare workers' characteristics } \\
\hline Male & & & 39 & 23 & & & & & 38 & 22 & & \\
\hline Age (year) & 47.1 & 8.5 & & & & & 47.3 & 8.5 & & & & \\
\hline Body mass index $\left(\mathrm{kg} / \mathrm{m}^{2}\right)$ & 24.4 & 3.7 & & & & & 24.3 & 4.5 & & & & \\
\hline \multicolumn{13}{|l|}{ Employment status } \\
\hline Administrative & & & 20 & 12 & & & & & 26 & 15 & & \\
\hline Caregivers and medical & & & 93 & 54 & & & & & 93 & 54 & & \\
\hline Technical & & & 58 & 34 & & & & & 52 & 31 & & \\
\hline Years in ongoing employment status & 16.0 & 11 & & & & & 18.0 & 12 & & & & \\
\hline Current smoker & & & 28 & 16 & & & & & 31 & 18 & & \\
\hline
\end{tabular}

${ }^{a}$ Analgesic, anti-inflammatory, myorelaxant, anti-depressant, anti-epileptic analgesic.

b Physiotherapy, osteopathy, lumbar belt, corset, infiltration, mesotherapy, manipulation, spinal traction.

Table 2. Recurrence of low-back pain (LBP) at 2-year follow-up. [OR $\mathrm{R}_{\mathrm{adj}}=$ adjusted odds ratio; $95 \% \mathrm{Cl}=95 \%$ confidence interval.]

\begin{tabular}{|c|c|c|c|c|c|c|c|}
\hline \multirow[t]{2}{*}{ Outcomes } & \multicolumn{2}{|c|}{ Intervention group $(\mathrm{N}=147)$} & \multicolumn{2}{|c|}{ Control group ( $\mathrm{N}=151)$} & \multirow[b]{2}{*}{$O R_{a d j}$} & \multirow[b]{2}{*}{$95 \% \mathrm{Cl}$} & \multirow[b]{2}{*}{ P-value } \\
\hline & N & $\%$ & $\mathrm{~N}$ & $\%$ & & & \\
\hline Workers with LBP recurrence ${ }^{a}$ & $121 / 133$ & 91 & $129 / 138$ & 93 & 0.68 & $0.27-1.69$ b & 0.405 \\
\hline Without sick leave ${ }^{c}$ & $106 / 124$ & 85 & $123 / 133$ & 92 & 0.44 & $0.19-1.03^{d}$ & 0.053 \\
\hline With sick leave & $35 / 147$ & 24 & $31 / 151$ & 21 & 1.22 & $0.67-2.22^{e}$ & 0.516 \\
\hline LBP recurrence with sick leave & & & & & 0.71 & $0.49-1.04^{f}$ & 0.079 \\
\hline 0 & $112 / 147$ & 76 & $120 / 151$ & 79 & & & \\
\hline 1 & $27 / 147$ & 18 & $13 / 151$ & 9 & & & \\
\hline 2 & $3 / 147$ & 2 & $8 / 151$ & 5 & & & \\
\hline$\geq 3$ & $5 / 147$ & 3 & $10 / 151$ & 6 & & & \\
\hline Workers with chronic evolution 9 & $6 / 147$ & 4 & $3 / 147$ & 2 & 3.56 & $0.70-18.2^{\mathrm{h}}$ & 0.127 \\
\hline
\end{tabular}

a Recurrence of LBP with or without sick leave, 27 with missing data (9\%).

${ }^{b}$ Logistic model adjusted for hospital anxiety and depression score for anxiety (HAD-A) ( $\left.N=268\right)$.

c 41 with missing data, item added during the study (14\%).

${ }^{d}$ Logistic model adjusted for HAD-A and work schedule (day/night/night and day) ( $\mathrm{N}=257,41$ missing data).

e Logistic model adjusted for age, number of sick leaves three years prior to inclusion, length of ongoing back pain and fear-avoidance beliefs question-

naire score for occupational activity ( $F A B Q-W)(N=294,4$ missing data).

f Poisson model adjusted for age, number of sick leaves three years prior to inclusion and length of ongoing back pain ( $N=298)$.

${ }^{9}$ Sick leave with duration $\geq 90$ days.

${ }^{\mathrm{h}}$ Logistic model adjusted for hospital anxiety and depression score for depression HAD-D (N=298). 
Table 3. Evolution of physical and psychosocial variables in the intervention and control groups. [SD=standard deviation; QDSA-S=SaintAntoine pain questionnaire sensory score; QDSA-A=Saint-Antoine pain questionnaire affective score; VAS=visual analog scale; FABQ$\mathrm{P}=$ fear-avoidance beliefs questionnaire score for physical activity; FABQ-W=fear-avoidance beliefs questionnaire score for occupational activity; HAD-D=hospital anxiety and depression score for depression; HAD-A=hospital anxiety and depression score for anxiety; CSQ= coping strategy questionnaire; SF-12=short form questionnaire; FTF=finger-to-floor.]

\begin{tabular}{|c|c|c|c|c|c|c|c|c|c|c|c|c|c|}
\hline & \multicolumn{6}{|c|}{ Intervention group $(\mathrm{N}=139)$} & \multicolumn{6}{|c|}{ Control group ( $\mathrm{N}=141)$} & \multirow[t]{3}{*}{ P-value ${ }^{2}$} \\
\hline & \multicolumn{2}{|c|}{ Baseline } & \multicolumn{2}{|c|}{ 18-month } & \multirow{2}{*}{$\begin{array}{c}\text { Mean } \\
\text { difference }\end{array}$} & \multirow[t]{2}{*}{$95 \% \mathrm{Cl}$} & \multicolumn{2}{|c|}{ Baseline } & \multicolumn{2}{|c|}{ 18-month } & \multirow{2}{*}{$\begin{array}{c}\text { Mean } \\
\text { difference }\end{array}$} & \multirow[t]{2}{*}{$95 \% \mathrm{Cl}$} & \\
\hline & Mean & SD & Mean & SD & & & Mean & SD & Mean & SD & & & \\
\hline \multicolumn{14}{|l|}{$\begin{array}{l}\text { Questionnaires (score range } \\
\text { from minimum-maximum) }\end{array}$} \\
\hline QDSA-S (0-36) & 8.5 & 6.1 & 7.3 & 6.3 & -1.4 & $-2.7--0.2^{\text {a }}$ & 8.5 & 5.7 & 8.1 & 6.4 & -0.2 & $-1.2-0.8$ & 0.4674 \\
\hline QDSA-A $(0-28)$ & 7.1 & 7.0 & 5.1 & 6.2 & -1.9 & $-3.1--0.6^{b}$ & 6.4 & 6 & 6.1 & 6.5 & -0.4 & $-1.6-0.8$ & 0.1323 \\
\hline VAS lumbar pain & 41.1 & 22.7 & 36.2 & 21.0 & -8.5 & $-16.7--0.3$ & 34.6 & 19.2 & 36.7 & 21 & 5.1 & $-2.6-12.7$ & 0.1417 \\
\hline VAS radicular pain & 39.8 & 19.6 & 44.2 & 15.8 & -0.8 & $-34.9-33.2$ & 40.5 & 20.8 & 41.5 & 27 & -4.3 & $-42.5-34.0$ & 0.7002 \\
\hline FABQ-P $(0-24)$ & 12.1 & 5.7 & 8.5 & 5.8 & -3.6 & $-4.8--2.4^{c}$ & 12.8 & 5.6 & 11.7 & 6.1 & -1.3 & $-2.2--0.3^{a}$ & $0.0119^{a}$ \\
\hline FABQ-W (0-42) & 16.4 & 9.7 & 14.4 & 10.2 & -1.9 & $-3.1--0.7^{b}$ & 17 & 9.2 & 15.7 & 9.9 & -1.1 & $-2.4-0.3$ & 0.7213 \\
\hline Quebec score $(0-100)$ & 24.7 & 14.0 & 19.8 & 15.8 & -5.0 & $-7.5--2.6^{c}$ & 26.6 & 15.3 & 24.4 & 16.4 & -2.8 & $-5.4--0.2^{a}$ & 0.3075 \\
\hline CSQ-Distraction (5-20) & 11.4 & 3.7 & 12.5 & 3.8 & 1.3 & $0.4-2.1^{\mathrm{a}}$ & 11.7 & 3.7 & 11.8 & 3.4 & -0.4 & $-1.2-0.3$ & 0.1410 \\
\hline CSQ-Reinterpreting (4-16) & 6.5 & 2.7 & 7.2 & 3.0 & 0.8 & $0.1-1.4^{a}$ & 6.4 & 2.6 & 6.9 & 2.8 & 0.3 & $-0.2-0.9$ & 0.5850 \\
\hline CSQ-Ignoring (5-20) & 12.1 & 3.6 & 12.1 & 3.3 & -0.3 & $-1-0.5$ & 11.9 & 3.2 & 11.7 & 3.2 & -0.2 & $-0.9-0.6$ & 0.8135 \\
\hline CSQ-Catastrophizing (4-16) & 7 & 2.3 & 6.3 & 2.3 & -0.8 & $-1.3--0.3^{c}$ & 6.7 & 2.2 & 6.4 & 2 & -0.5 & $-0.9-0.0^{b}$ & 0.4978 \\
\hline CSQ-Praying (3-12) & 4.5 & 2.1 & 4.3 & 2.1 & -0.3 & $-0.6-0.0$ a & 4.6 & 2.3 & 4.3 & 2.1 & -0.3 & $-0.7-0.1$ & 0.7755 \\
\hline SF-12 Physical $(0-100)$ & 44.8 & 7.5 & 47.4 & 7.7 & 2.4 & $0.9-3.8^{b}$ & 44.3 & 7.3 & 45.1 & 8.3 & 0.8 & $-0.5-2.0$ & 0.1647 \\
\hline SF-12 Mental $(0-100)$ & 44.4 & 10.6 & 45.8 & 11.7 & 1.1 & $-0.6-2.9$ & 44.7 & 9.9 & 44 & 11 & -0.6 & $-2.5-1.3$ & 0.2595 \\
\hline HAD-A (0-21) & 11.1 & 2.4 & 11.3 & 2.3 & -0.1 & $-0.4-0.3$ & 11.2 & 2.2 & 11.6 & 2.2 & 0.2 & $-0.2-0.5^{a}$ & 0.7100 \\
\hline HAD-D (0-21) & 9.1 & 1.7 & 9 & 1.8 & 0.2 & $-0.2-0.6$ & 8.5 & 5.7 & 8.1 & 6.4 & 0.4 & $0.0-0.7$ & 0.3408 \\
\hline \multicolumn{14}{|l|}{ Physical parameters } \\
\hline FTF distance $(\mathrm{cm})$ & 8.1 & 11.2 & 6.9 & 10.4 & -1.2 & $-2.5-0.1^{\text {a }}$ & 10.4 & 11.8 & 8.7 & 10.6 & -1.7 & $-3.2--0.2$ & 0.8236 \\
\hline Schöber Mac Rae (cm) & 20 & 3 & 19.9 & 3.2 & -0.2 & $-0.9-0.5$ & 19.7 & 3.6 & 19.6 & 3.8 & -0.1 & $-1.0-0.7$ & 0.9324 \\
\hline Shirado (s) & 119 & 92 & 127 & 84 & 9.7 & $-5.8-25.2$ & 117 & 92 & 108 & 82 & -10.2 & $-24.6-4.2$ & 0.2479 \\
\hline Sorensen (s) & 92 & 53 & 105 & 58 & 13.9 & $3.3-24.5^{b}$ & 86 & 53 & 79 & 56 & -8.3 & $-17.5-0.9$ & $0.0276^{a}$ \\
\hline
\end{tabular}

a Difference-in-difference (DID) analysis to compare the trend in intervention group from pre-implementation (baseline) and intervention period

(18-month) with the trend in control group from pre-implementation (baseline) and intervention period (18-month). DID tests an intervention effect after controlling for temporal trend between periods.

b $P<0.05$.

c $P<0.01$.

d $P<0.001$.

the baseline characteristics of the participants, without significant differences between groups. At 2-year follow-up, a total of 44 (13\%) participants had dropped out. More than half of the dropouts were due to uncontrollable reasons (retirement, lay-off, and job transfer). Finally, a total of 298 participants (87\%) had complete data for the analysis of the primary outcome.

\section{LBP recurrence outcomes}

The recurrence rate of LBP (with or without sick leave) at 2-year follow-up and the rate of chronicization (sick leave due to LBP $>3$ months) are summarized in table 2. From baseline to 2 -year follow-up, 35 workers (24\%) in the intervention group and 31 workers $(21 \%)$ in the control group had $\geq 1$ recurrence of LBP with sick leave. After adjusting for baseline characteristics, no effect was observed between groups (OR 1.22, 95\% CI 0.67-2.23, $\mathrm{P}=0.516$ ). The mean duration of sick leaves due to LBP episodes was comparable between groups [25, standard deviation (SD) 50 days in the control group compared with 32 ( $\mathrm{SD} 65$ ) days in the intervention group, $\mathrm{P}=0.940$ ].
Additionally, the time from inclusion to the first recurrence of LBP with sick leave was similar between groups [11.8 (SD 7.8) months and 13.4 (SD 8.2) months in the control and intervention group, respectively; $\mathrm{P}=0.511$, log-rank test]. The reduction of recurrence of LBP episode without sick leave in the intervention group $(\mathrm{N}=106)$ as compared to the control group $(\mathrm{N}=123)$ almost reached statistical significance $(\mathrm{P}=0.053)$. Neither the per-protocol nor sensitivity analyses showed significant differences between groups.

\section{Psychological outcomes}

Participants from the intervention $(\mathrm{N}=139 ; 81 \%)$ and control $(\mathrm{N}=141 ; 82 \%)$ groups were assessed at baseline and 18 months for a range of parameters shown in table 3. All of the significant differences that were observed were in favor of the intervention. The intervention group showed a significant improvement for the FABQ-P score with a mean reduction of $-3.6(95 \% \mathrm{CI}-4.8--2.4)$ compared to $-1.3(95 \% \mathrm{CI}-2.2--0.3)$ in the control group $(\mathrm{P}<0.05)$. 
Table 4. Exercise training sessions observance rates over time. [ $S \mathrm{D}=$ standard deviation; $Q 1-Q 3=$ interquartile range between $1^{\text {st }}$ and $3^{\text {rd }}$ quartiles; Min-Max=minimum-maximum.]

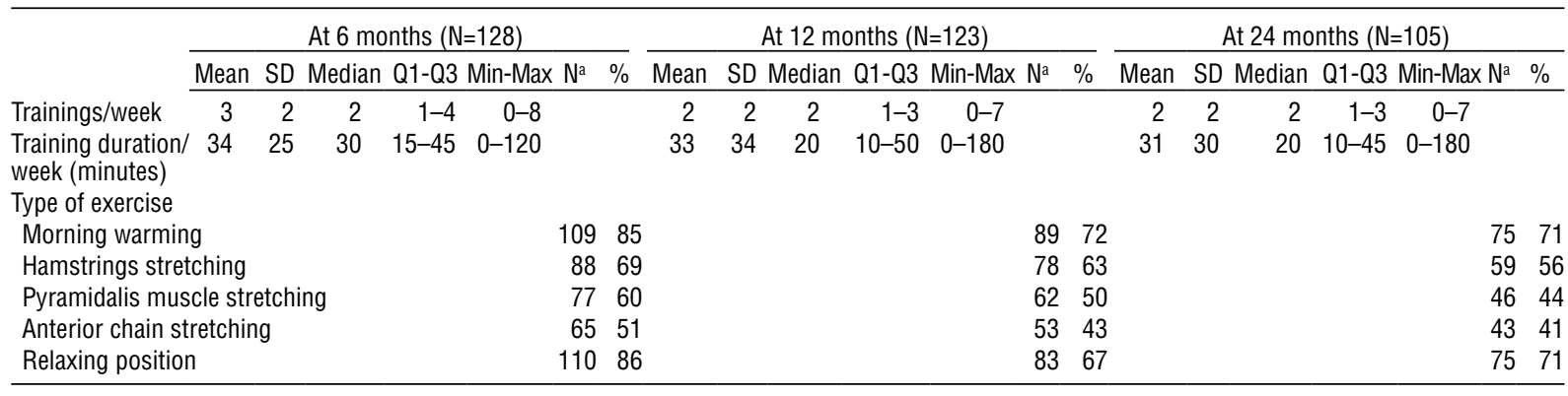

a Number of participants.

\section{Physical outcomes}

For physical parameters, the Sorensen test was significantly improved after the intervention with a mean increase of 13.9 minutes ( $95 \%$ CI 3.3-24.5) in the intervention group versus -8.3 minutes $(95 \% \mathrm{CI}-17.5-0.9)$ in the control group $(\mathrm{P}<0.05)$.

\section{Functional outcomes}

The difference observed for the QBPDS was not statistically significant.

\section{Healthcare utilization}

Significantly less workers in the intervention group had visited a $\mathrm{GP}(42 \%$ versus $57 \%, \mathrm{P}=0.002)$ or specialist ( $18 \%$ versus $34 \%, \mathrm{P}=0.011)$ at least once for their LBP at 2-year follow-up. The intervention group also reported significantly less physiotherapy visits $(28 \%$ versus $50 \%$ with $\geq 1$ visit; $\mathrm{P}<0.001)$ and imagery tests $(15 \%$ versus $26 \%, \mathrm{P}=0.038$ ) for their LBP as compared to the control group. Fewer participants in the intervention group took pain killers ( $68 \%$ versus $77 \%, \mathrm{P}=0.039)$ but no difference was observed for anti-inflammatory medication.

\section{Process evaluation (attendance, observance, satisfaction)}

Attendance indicators showed that 125 subjects (73\%) participated in all training sessions in the intervention group, $16(9 \%)$ missed one of the two sessions where absence was tolerated (session 3 or 4), 18 (11\%) discontinued the program and $12(7 \%)$ attended none of the sessions. Healthcare workers who discontinued the program attended three sessions on average (minimum-maximum: $1-5)$. In total, $141(82 \%)$ participants in the intervention group were considered per-protocol. Observance of the home-based exercises was modest and decreased significantly over time as shown in table 4, both in terms of frequency and variety of exercises. The satisfaction survey at six months after the last training session showed that $92 \%$ of the workers who attended at $\geq 1$ session were satisfied with the program and $83 \%$ were satisfied with its effects on their health status (response rate $81 \%, 128 / 159$ ).

The qualitative evaluation of the semi-structured interviews revealed that workplace location and worktime schedule of the training sessions were major facilitators of the participants' attendance, as well as encouragement from other members in the group (26). The home-based part of the intervention was more problematic as several participants mentioned a lack of sufficient technical autonomy to perform the exercises on their own as well as insufficient social reinforcement to motivate them exercising in the long term. One theory limitation of the program was the overestimation of the observance of home-based exercises. The absence of a component to address biomechanical and/or psychosocial risk factors of LBP in the workplace was also questioned (26).

\section{Discussion}

The results of our study could not confirm our initial hypothesis that a brief workplace-based cognitive and exercise intervention, followed by a home-based exercise program, is effective in secondary prevention to reduce LBP recurrence with sick-leave among healthcare workers with a previous history of LBP. Three main lines of arguments may help understand the absence of positive effects for LBP recurrence outcomes.

First, the population included in the study differs from what was expected and presents several characteristics of heterogeneity. The mean number of painful days per month at baseline was surprisingly high in both groups (6.2 and 6.5 in the intervention and control group, respectively). The baseline levels of fearavoidance beliefs, functional capacity, and pain intensity (table 3) were similar to those observed among subacute 
or chronic LBP patients in previous French studies (23, 28-32). Thus, the population of our study is likely to be a mix of pain-free workers (as expected) with other workers suffering from "highly recurrent" LBP. Reasons for this unexpected heterogeneity may pertain to the difficult issue of LBP case definition (33), and the pressure on the OP to include workers, maybe to the detriment of the strict application of inclusion/exclusion criteria. As a consequence of this heterogeneity, we may assume that the brief intervention was "too light" to be effective in a population that was more severe than expected. This assumption is corroborated by the poor observance of the home-based exercises, which weakens their potential effects (26), and by the comparison to other programs in secondary prevention of LBP, the duration and intensity of which were higher than in our brief intervention (12).

Second, the absence of a component in the intervention pertaining to workplace physical and psychosocial risk factors of LBP may partly explain its absence of effect on LBP recurrence, despite the advantage of the program being delivered in the workplace and during working hours.

Third, the more important use of healthcare in the control group may have contributed to lower LBP recurrence with sick leave in this group, thus masking the relative effect of the intervention.

Last, the expected number of participants could not be included due to an overestimation of the recurrence rate of LBP episodes with sick leave in the power calculation, resulting in the inability to confirm or reject our hypothesis from a strict statistical point of view.

However, some other positive results of the PRESLO program are worthwhile mentioning. A significant reduction of healthcare utilization was achieved by the intervention (medical and physiotherapist visits, imaging, pain killers), in line with a reduction in physical fear-avoidance beliefs. These results are congruent with a modest but significant gain in physical parameters (Sorensen test). In view of these convergent and positive results, we believe that the PRESLO program can be considered an effective intervention to correct fearavoidance beliefs of workers with previous history of LBP, improve their muscle endurance, and reduce their healthcare utilization.

\section{Strengths and limitations}

The main limitations of our study pertain to the lack of statistical power resulting in an inability to conclude about the main outcome of LBP recurrence with sickleave, the inclusion of more severe cases than expected, and program theory limitations about the home-based component of the intervention.

The main strengths of our study are its standards of methodological rigor and the adherence to the $\mathrm{CON}$ -
SORT checklist. As such, the positive results of the PRESLO program on secondary outcomes are reliable and likely to have important spin-offs.

\section{Recommendations for future research}

Based on our results, we can recommend a careful case definition of workers with previous history of LBP (33) and a better characterization of this subgroup (34) allowing a stepped secondary prevention similar to the primary care stratification developed in LBP (35-37). Another recommendation is to investigate the value of a workplace component to address the physical and psychosocial factors of LBP among workers still at work, as this component has proven its value in other LBP populations $(10,11)$. Specific attention should be paid to ensure the technical skills of the participants in the realization of their exercises. The logic model of future interventions should be carefully thought ahead (38) with a clear integration of mechanisms to improve participants' motivation and observance (39-41).

\section{Concluding remarks}

It was not possible to assess the effectiveness of a light exercise program, initiated in the workplace and continued at home, in reducing LBP recurrence episodes in the long-term among healthcare workers. However, this program was effective in improving muscle endurance and reducing fear-avoidance beliefs and GP and physiotherapy visits as well as pain medication. Further studies are necessary to better characterize the subgroup of workers with highly recurrent LBP and their needs in order to develop effective interventions to reduce LBP recurrence and related sick-leave.

\section{Acknowledgements}

This work was supported by grants received from the Fonds National de prévention, ANSES and CLACTHCL 2010-2012

The authors are grateful to Marie-Annick Le Pogam, the workers who participated in the study, the direction of the Hospices civils de Lyon, the physiotherapists who delivered the intervention, the occupational physicians who included the workers, and the persons who helped in the study. 


\section{References}

1. Hoy D, Brooks P, Blyth F, Buchbinder R. The epidemiology of low back pain. Baillieres Best Pract Res Clin Rheumatol. 2010;6:769-81. http://dx.doi.org/10.1016/j. berh.2010.10.002.

2. Gourmelen J, Chastang JF, Ozguler A, Lanoë JL, Ravaud JF, Leclerc A. Fréquence des lombalgies dans la population française de 30 à 64 ans. Résultats issus de deux enquêtes nationales [Frequency of low back pain among men and women aged 30 to 64 years in France. Results of two national surveys]. Ann Readapt Med Phys. 2007;8:640-4. http:// dx.doi.org/10.1016/j.annrmp.2007.05.009.

3. Palazzo C, Ravaud JF, Papelard A, Ravaud P, Poiraudeau S. The burden of musculoskeletal conditions. PLoS ONE. 2014;3:e90633. http://dx.doi.org/10.1371/journal. pone. 0090633 .

4. Burton AK, Balague F, Cardon G, Eriksen HR, Henrotin Y, Lahad A, et al. Chapter 2. European guidelines for prevention in low back pain. Eur Spine J. 2006;Suppl 2:S136-68. http:// dx.doi.org/10.1007/s00586-006-1070-3.

5. Mairiaux P, Loomis D, Mairiaux P, Loomis D. Randomised trials on secondary prevention of low back pain in occupational settings. Occup Environ Med. 2012;1:1-2. http://dx.doi. org/10.1136/oemed-2011-100248.

6. Hayden JA, Chou R, Hogg-Johnson S, Bombardier C. Systematic reviews of low back pain prognosis had variable methods and results: guidance for future prognosis reviews. J Clin Epidemiol. 2009;8:781-96.

7. Chou R, Shekelle P. Will this patient develop persistent disabling low back pain? JAMA. 2010;13:1295-302. http:// dx.doi.org/10.1001/jama.2010.344.

8. Melloh M, Elfering A, Egli Presland C, Roeder C, Barz T, Rolli Salathe $\mathrm{C}$, et al. Identification of prognostic factors for chronicity in patients with low back pain: a review of screening instruments. Int Orthop. 2009;2:301-13. http://dx.doi. org/10.1007/s00264-008-0707-8.

9. Kamper SJ, Apeldoorn AT, Chiarotto A, Smeets RJ, Ostelo RW, Guzman J, et al. Multidisciplinary biopsychosocial rehabilitation for chronic low back pain: Cochrane systematic review and meta-analysis. BMJ. 2015:h444. http://dx.doi. org/10.1136/bmj.h444.

10. Schaafsma FG, Whelan K, van der Beek AJ, van der EsLambeek LC, Ojajarvi A, Verbeek JH. Physical conditioning as part of a return to work strategy to reduce sickness absence for workers with back pain. Cochrane Database Syst Rev. 2013:CD001822. http://dx.doi.org/10.1002/14651858. cd001822.pub3.

11. van Vilsteren $\mathrm{M}$, van Oostrom $\mathrm{SH}$, de Vet HC, Franche RL, Boot CR, Anema JR. Workplace interventions to prevent work disability in workers on sick leave. Cochrane Database Syst Rev. 2015:Cd006955. http://dx.doi.org/10.1002/14651858. cd006955.pub3.

12. Choi B, Verbeek JH, Tam W, Jiang J. Exercises for prevention of recurrences of low-back pain. Cochrane Database Syst Rev. 2010. http://dx.doi.org/10.1002/14651858.CD006555.pub2.

13. Soukup MG, Glomsrod B, Lonn JH, Bo K, Larsen S. The effect of a Mensendieck exercise program as secondary prophylaxis for recurrent low back pain. A randomized, controlled trial with 12-month follow-up. Spine. 1999;15:1585-91; discussion 1592. http://dx.doi.org/10.1097/00007632-199908010-00013.

14. Kellett KM, Kellett DA, Nordholm LA. Effects of an exercise program on sick leave due to back pain. Physical Therapy. 1991;4:283-91.

15. Andersen LL, Burdorf A, Fallentin N, Persson R, Jakobsen MD, Mortensen OS, et al. Patient transfers and assistive devices: prospective cohort study on the risk for occupational back injury among healthcare workers. Scand J Work Environ Health. 2014;1:74-81. http://dx.doi.org/10.5271/sjweh.3382.

16. Yassi A, Lockhart K. Work-relatedness of low back pain in nursing personnel: a systematic review. Int J Occup Environ Health. 2013;3:223-44. http://dx.doi.org/10.1179/20493967 13 Y.0000000027.

17. Vinck L. Occupational risk exposures: Work atmosphere and physical constraints [Les expositions aux risques professionnels: Les ambiances et contraintes physiques]. Synthèse. Stat'. 2014;8:186.

18. Denis A, Zelmar A, Le Pogam M-A, Chaleat-Valayer E, Bergeret A, Colin C. The PRESLO study: evaluation of a global secondary low back pain prevention program for health care personnel in a hospital setting. Multicenter, randomized intervention trial. BMC Musculoskelet Disord. 2012;1:1-10. http://dx.doi.org/10.1186/1471-2474-13-234.

19. Coudeyre E, Givron P, Gremeaux V, Lavit P, Herisson C, Combe B, et al. Traduction française et adaptation culturelle du "back book" [French translation and cultural adaptation of the "Back Book"]. Ann Readapt Med Phys. 2003;8:553-7. http:// dx.doi.org/10.1016/j.annrmp.2003.02.001.

20. Boureau F, Luu M, Doubrere JF, Gay C. Elaboration d'un questionnaire d'auto-evaluation de la douleur par liste de qualificatifs [Construction of a questionnaire for the self-evaluation of pain using a list of qualifiers]. Therapie. 1984;2:119-29.

21. Zigmond AS, Snaith RP. The Hospital Anxiety and Depression Scale. Acta Psychiatr Scand. 1983;6:361-70. http://dx.doi. org/10.1111/j.1600-0447.1983.tb09716.x.

22. Irachabal S, Koleck M, Rascle N, Bruchon-Schweitzer M. Strategies de coping des patients douloureux: adaptation francaise du coping strategies questionnaire (CSQ-F) [Pain coping strategies: French adaptation of the coping strategies questionnaire (CSQ-F)]. Encephale. 2008;1:47-53. http:// dx.doi.org/10.1016/j.encep.2006.11.002.

23. Chaory K, Fayad F, Rannou F, LefAvre-Colau MM, Fermanian $\mathrm{J}$, Revel M, et al. Validation of the French version of the fear avoidance belief questionnaire. Spine. 2004;8:908-13. http:// dx.doi.org/10.1097/00007632-200404150-00018.

24. Gandek B, Ware JE, Aaronson NK, Apolone G, Bjorner JB, Brazier JE, et al. Cross-validation of item selection and scoring for the SF-12 Health Survey in nine countries: results from the IQOLA Project. International Quality of Life Assessment. J 
Clin Epidemiol. 1998;11:1171-8. http://dx.doi.org/10.1016/ S0895-4356(98)00109-7.

25. Kopec JA, Esdaile JM, Abrahamowicz M, Abenhaim L, WoodDauphinee S, Lamping DL, et al. The Quebec Back Pain Disability Scale: conceptualization and development. J Clin Epidemiol. 1996;2:151-61. http://dx.doi.org/10.1016/08954356(96)00526-4.

26. François A, Fassier JB, Chaléat-Valayer E, Siani F, Colin C, Bergeret A. Le programme PRESLO de prévention secondaire des lombalgies : évaluation du point de vue des usagers [The PRESLO program in secondary prevention of low back pain: evaluation from the users' point of view]. Archives des Maladies Professionnelles et de l'Environnement. 2014;4:37181. http://dx.doi.org/10.1016/j.admp.2013.10.006.

27. Puhani PA. The treatment effect, the cross difference, and the interaction term in nonlinear "difference-in-differences" models. Economics Letters. 2012;1:85-7. http://dx.doi. org/10.1016/j.econlet.2011.11.025.

28. Gremeaux V, Benaim C, Poiraudeau S, Herisson C, Dupeyron A, Coudeyre E. Evaluation of the benefits of low back pain patients' education workshops during spa therapy. Joint Bone Spine. 2013;1:82-7. http://dx.doi.org/10.1016/j. jbspin.2011.12.014.

29. Genet F, Autret K, Roche N, Lapeyre E, Schnitzler A, Mandjui B, et al. Comparison of the repercussions of cLBP in four French-speaking countries. Ann Phys Rehabil Med. 2009;10:717-28. http://dx.doi.org/10.1016/j. rehab.2009.08.002.

30. Chaory K, Rannou F, Fermanian J, Genty M, Rosenberg $\mathrm{S}$, Billabert $\mathrm{C}$, et al. Impact de programmes de restauration fonctionnelle sur les peurs, croyances et conduites d'évitement $\mathrm{du}$ lombalgique chronique [Impact of functional restoration programs on fears, avoidance and beliefs in chronic low back pain patients]. Ann Readapt Med Phys. 2004;3:93-7. http:// dx.doi.org/10.1016/j.annrmp.2003.10.007.

31. Poiraudeau S, Rannou F, Baron G, Le Henanff A, Coudeyre E, Rozenberg S, et al. Fear-avoidance beliefs about back pain in patients with subacute low back pain.[see comment]. Pain. 2006;3:305-11. http://dx.doi.org/10.1016/j. pain.2006.04.019.

32. Gremeaux V, Coudeyre E, Viviez T, Bousquet PJ, Dupeyron A. Do Teaching General Practitioners' Fear-Avoidance Beliefs Influence Their Management of Patients with Low Back Pain? Pain Pract. 2014.
33. Videman T, Battie MC. Commentary: back pain epidemiology-the challenge of case definition and developing new ideas. Spine Journal. 2012;1:71-2. http://dx.doi.org/10.1016/j. spinee.2011.12.007.

34. Steenstra IA, Knol DL, Bongers PM, Anema JR, van Mechelen W, de Vet HC, et al. What works best for whom? An exploratory, subgroup analysis in a randomized, controlled trial on the effectiveness of a workplace intervention in low back pain patients on return to work. Spine. 2009;12:1243-9. http://dx.doi.org/10.1097/BRS.0b013e3181a09631.

35. Morso L, Kent P, Manniche C, Albert HB. The predictive ability of the STarT Back Screening Tool in a Danish secondary care setting. Eur Spine J. 2014;1:120-8. http:// dx.doi.org/10.1007/s00586-013-2861-y.

36. Bruyere O, Demoulin M, Beaudart C, Hill JC, Maquet D, Genevay S, et al. Validity and reliability of the French version of the STarT Back screening tool for patients with low back pain. Spine (Phila Pa 1976). 2014;2:E123-8. http://dx.doi. org/10.1097/BRS.0000000000000062.

37. Hill JC, Whitehurst DG, Lewis M, Bryan S, Dunn KM, Foster $\mathrm{NE}$, et al. Comparison of stratified primary care management for low back pain with current best practice (STarT Back): a randomised controlled trial. Lancet. 2011;9802:1560-71. http://dx.doi.org/10.1016/S0140-6736(11)60937-9.

38. Rossi PH. Expressing and assessing program theory, in Evaluation : a systematic approach. Sage ; 2014. p. 133-68.

39. Jakobsen MD, Sundstrup E, Brandt M, Jay K, Aagaard P, Andersen LL. Effect of workplace- versus home-based physical exercise on musculoskeletal pain among healthcare workers: a cluster randomized controlled trial. Scand J Work Environ Health. 2015;2:153-63. http://dx.doi.org/10.5271/ sjweh.3479.

40. McLean SM, Burton M, Bradley L, Littlewood C, McLean SM, Burton M, et al. Interventions for enhancing adherence with physiotherapy: a systematic review. Manual Ther. 2010;6:514 21. http://dx.doi.org/10.1016/j.math.2010.05.012.

41. Jack K, McLean SM, Moffett JK, Gardiner E, Jack K, McLean SM, et al. Barriers to treatment adherence in physiotherapy outpatient clinics: a systematic review. Manual Ther. 2010;3:220-8. http://dx.doi.org/10.1016/j. math.2009.12.004.

Received for publication: 6 June 2016 